\title{
Cellulose nanocrystals: synthesis, functional properties, and applications
}

This article was published in the following Dove Press journal:

Nanotechnology, Science and Applications

4 November 2015

Number of times this article has been viewed

\section{Johnsy George \\ SN Sabapathi}

Food Engineering and Packaging Division, Defence Food Research Laboratory, Siddarthanagar, Mysore, Karnataka, India
Correspondence: Johnsy George Food Engineering and Packaging Division, Defence Food Research Laboratory, Bannur Road, Siddarthanagar, Mysore 570 0I I, Karnataka, India Email g.johnsy@gmail.com

\begin{abstract}
Cellulose nanocrystals are unique nanomaterials derived from the most abundant and almost inexhaustible natural polymer, cellulose. These nanomaterials have received significant interest due to their mechanical, optical, chemical, and rheological properties. Cellulose nanocrystals primarily obtained from naturally occurring cellulose fibers are biodegradable and renewable in nature and hence they serve as a sustainable and environmentally friendly material for most applications. These nanocrystals are basically hydrophilic in nature; however, they can be surface functionalized to meet various challenging requirements, such as the development of high-performance nanocomposites, using hydrophobic polymer matrices. Considering the ever-increasing interdisciplinary research being carried out on cellulose nanocrystals, this review aims to collate the knowledge available about the sources, chemical structure, and physical and chemical isolation procedures, as well as describes the mechanical, optical, and rheological properties, of cellulose nanocrystals. Innovative applications in diverse fields such as biomedical engineering, material sciences, electronics, catalysis, etc, wherein these cellulose nanocrystals can be used, are highlighted.
\end{abstract}

Keywords: sources of cellulose, mechanical properties, liquid crystalline nature, surface modification, nanocomposites

\section{Introduction}

Cellulose is the most abundant natural polymer available on the earth and it is an important structural component of the cell wall of various plants. Apart from plants, cellulose is also present in a wide variety of living species, such as algae, fungi, bacteria, and even in some sea animals such as tunicates. ${ }^{1}$ Cellulose is a fibrous, tough, and water-insoluble polymer and it plays an essential role in maintaining the structure of plant cell walls. Moreover, cellulose is a biodegradable, biocompatible, and renewable natural polymer and hence it is considered an alternate to nondegradable fossil fuel-based polymers. The chemical structure of cellulose (Figure 1) shows that the polymer, formed by condensation, consists of monomers joined together by glycosidic oxygen bridges. Cellulose is composed of $\beta$-1,4-linked glucopyranose units that form a high-molecular-weight linear homopolymer, in which every monomer unit is corkscrewed at $180^{\circ}$ with respect to its neighbors. ${ }^{2}$ The repeating unit of this natural polymer is a dimer of glucose, known as cellobiose. The degree of polymerization of cellulose can vary depending on the source and it is approximately 10,000 glucose units for wood-derived cellulose and 15,000 units for cotton-derived cellulose. ${ }^{3}$ Each glucopyranose unit bears three hydroxyl groups, which impart cellulose some of the characteristic properties such as hydrophilicity, chirality, biodegradability, etc, which 


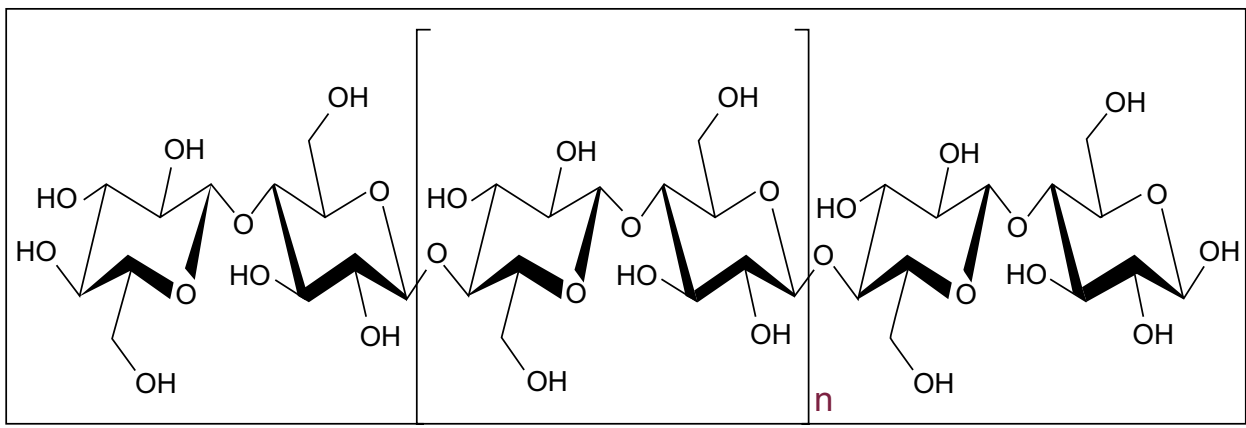

Figure I The chemical structure of cellulose, which is a linear polymer made up of $\beta$-D-glucopyranose units covalently linked with (I-4) glycosidic bonds.

are initiated by the high reactivity of the hydroxyl groups. ${ }^{1}$ The ability of these hydroxyl groups to form strong hydrogen bonds is the main reason for some other properties such as multiscale microfibrillated structure, hierarchical organization (crystalline and amorphous fractions), and highly cohesive nature. ${ }^{4}$

\section{Main sources of cellulose}

The main sources of cellulose are plants; however, algae, bacteria, and some sea animals are also capable of producing cellulose in large quantities. ${ }^{5} \mathrm{~A}$ brief description about the main sources is as follows.

\section{Plants}

Plants are the potential main sources of cellulose because they are abundant and relatively cheap. The main source of cellulose is wood pulp and cotton fibers. Large-scale industrial infrastructures are presently available for their harvesting, processing, and extraction. A wide variety of other plant materials such as jute, ramie, sisal, flax, hemp, etc are also well known sources for cellulose production. ${ }^{6}$ Other cellulose-producing plants include water plants, grasses, and some parts of plants such as leaves, stem, fruit, etc. Agricultural wastes such as wheat and rice straw, sugarcane bagasse, sawdust, cotton stables, etc are also used for the production of cellulose.

\section{Algae}

Native cellulose is a major component of the cell wall of many types of algae, which are highly crystalline. Various types of algae such as red, green, and yellow are known for cellulose production; however, green algae are the most preferred ones for cellulose extraction. Common cellulose-producing algae belong to the orders Cladophorales (Cladophora, Chaetomorpha, Rhizoclonium, and Microdyction) and Siphonocladales (Valonia, Dictyosphaeria, Siphonocladus, and Boergesenia). ${ }^{7}$ The cellulose derived from Valonia or Cladophora possesses an exceptionally high degree of crystallinity, which can be as high as $95 \%{ }^{8}$ Depending on the biosynthesis process occurring in different species, the properties of cellulose microfibrils obtained may also differ.

\section{Bacteria}

Certain species of bacteria, eg, Komagataeibacter xylinus, which occur as contaminants during vinegar fermentation, are well known for producing cellulose by utilizing a large variety of nitrogen and carbon sources. ${ }^{9}$ K. xylinus produces cellulose microfibrils in the form of clear, flat, and thick pellicles floating on the surface of the growth medium. ${ }^{10}$ These cellulose pellicles comprise pure cellulose along with a large proportion of water and other ingredients of the medium. Dilute alkaline solutions are capable of hydrolyzing and removing the impurities present in the cellulose pellicle. ${ }^{11}$ After alkali treatment and washing, the cellulose pellicles can be dried and processed into pure cellulose membranes. Microbially derived cellulose is unique and has several advantages over plant-derived cellulose as the former possesses better properties such as 1) unique nanostructure, 2) purity, 3) higher-dimensional stability, 4) greater mechanical strength, and 5) greater capacity to hold water. ${ }^{12}$ Microbial cellulose is identical to plant cellulose in terms of its molecular formula and polymeric structure, but the two forms differ in the arrangement of glycosyl units within the unit cells of the crystallites, which leads to higher crystallinity of the former. Compared to plant cellulose, microbial cellulose also exhibits a high degree of polymerization and superior properties.

\section{Tunicates}

Tunicates are marine invertebrate sea animals that are well known for producing cellulose in large amounts. These animals have a thick, leathery mantle, which is a good source of cellulose. Cellulose acts as a skeletal structure in the tunic tissues, which is a unique integumentary tissue that covers the entire epidermis of the tunicates. ${ }^{13}$ Cellulose is produced by these animals using enzyme complexes present in the 
membrane of the epidermis. Large numbers of tunicate species are available in nature and the properties of cellulose obtained can vary from species to species. The structure and properties of the cellulose microfibrils obtained from different species are often comparable, but small differences in the cellulose microfibril formation process may affect the final properties of microfibrils.

\section{Hierarchical arrangement of cellulose}

Cellulose is synthesized as individual molecules with a long chain, but it undergoes spinning in a hierarchical order at the site of biosynthesis to form assemblies of cellulose fibers. Many individual cellulose chains assemble together to form elementary fibrils (protofibrils), having an approximate diameter of $3.5 \mathrm{~nm} .{ }^{14}$ Depending on the source, the elementary fibrils' diameter can vary in the range of $2-20 \mathrm{~nm}$, and they are found in different packing arrangements depending on the conditions that govern biosynthesis. The microfibrils are formed by the aggregation of elementary fibrils by coalescence, which is used as a mechanism to reduce the free energy of the surfaces. ${ }^{15}$ This aggregation phenomenon is supported by van der Waals forces, as well as intra- and intermolecular hydrogen bonds. The cellulose molecules that are aggregated to form microfibrils have different orientations depending on the source. The microfibril aggregates also consist of tightly packed cellulose chains that form crystallites, which are stabilized by complex and strong hydrogen bonds, along with some less-ordered chains that form amorphous regions. ${ }^{16}$ Depending on the inter- and intramolecular interactions and molecular orientations present, cellulose can exist as different polymorphs or allomorphs. Already six interchangeable polymorphs, viz, cellulose I, II, $\mathrm{III}_{\mathrm{I}}, \mathrm{III}_{\mathrm{II}}, \mathrm{IV}_{\mathrm{I}}$, and $\mathrm{IV}_{\mathrm{II}}$ have been identified, the contents of which vary depending on the source of cellulose. ${ }^{17}$ Native cellulose generally has the crystal structure of cellulose I, but it is again subdivided into allomorphs I $\alpha$ and I $\beta .{ }^{18}$ Cellulose I $\alpha$ possesses a triclinic structure, whereas $\mathrm{I} \beta$ has a monoclinic crystalline structure. ${ }^{19}$ Cellulose obtained from microbial and algal sources is rich in I $\alpha$, while cellulose forming cell walls of higher plants is rich in $\mathrm{I} \beta$. These microfibrils assemble into larger units called macrofibrils, and they in turn further assemble together to form the familiar cellulose fibers.

\section{Cellulose nanocrystals and their isolation}

Naturally occurring bulk cellulose consists of highly ordered, crystalline regions along with some disordered (amorphous) regions in varying proportions, depending on its source..$^{20}$
When these microfibrils are subjected to a proper combination of mechanical, chemical, and enzyme treatments, the highly crystalline regions of the cellulose microfibrils can be extracted, resulting in the formation of cellulose nanocrystals (CNCs). ${ }^{21}$ CNCs are stiff rod-like particles consisting of cellulose chain segments in a nearly perfect crystalline structure. These nanocrystals are also referred to as whiskers, nanoparticles, nanofibers, microcrystallites, and so on, but the most widely accepted nomenclature is $\mathrm{CNCs} .{ }^{2}$ Compared to bulk cellulose, which has greater amorphous fractions, these nanocrystals exhibit high specific strength, modulus, high surface area, and unique liquid crystalline properties.

Several mechanical processes, such as high-pressure homogenizations, high-intensity ultrasonic treatments, microfluidization techniques, cryocrushing, etc, have been utilized for the extraction of cellulose microfibrils. These mechanical processes produce enough shear forces to split apart the cellulose fibers along the longitudinal axis and help to extract the cellulose microfibrils. Each cellulose microfibril is devoid of chain folding and can be considered a string of cellulose crystals, linked along the microfibril by disordered or paracrystalline regions. ${ }^{22}$ The chemical method of converting cellulose microfibrils into CNCs is better than the mechanical methods as the former reduces energy consumption and also produces rod-like short nanocrystals with improved crystallinity. Ribbon-like nanofiber samples obtained from wood-derived cellulose after mechanical refining exhibit a lower crystalline fraction (0.05-0.55) compared to rod-like wood $\mathrm{CNC}(0.6)$ obtained after acid hydrolysis. ${ }^{23}$ Strong acid hydrolysis is usually used for the removal of amorphous domains that are regularly distributed along the microfibrils. Strong acids can easily penetrate into the amorphous regions having a low level of order and hydrolyze them, leaving the crystalline regions unaffected.

Colloidal suspensions of cellulose were first synthesized by Ranby $^{24}$ in 1951 by using a controlled sulfuric acidcatalyzed degradation of cellulose fibers. The degradation induced by boiling cellulose fibers in acidic solution reached a limit after a certain period of treatment. Transmission electron microscopy and electron diffraction studies confirmed the presence of needle-shaped cellulose particles, which possessed the same crystalline structure as the original cellulose fibers. ${ }^{25,26}$ Acid hydrolysis of cellulose, followed by ultrasound sonication, later led to the development of microcrystalline cellulose. ${ }^{27}$ The differences in the kinetics of hydrolysis between amorphous and crystalline domains led to the selective cleavage of cellulose chains ${ }^{28}$ As a result of acid hydrolysis, a rapid decrease in the degree of polymerization 
was observed, which reached a cutoff level known as the level-off degree of polymerization (LODP). The value of LODP varies depending on the cellulose origin, where cottonderived cellulose possesses an LODP of 250, 300 for ramie fibers, 140-200 for bleached wood pulp fibers, and up to 6,000 for cellulose obtained from Valonia. ${ }^{29-32} \mathrm{CNCs}$ obtained by the acid hydrolysis of cellulose from bacteria, tunicates, or Valonia exhibit a high polydispersity in the molecular weight, without any evidence of the LODP, probably due to the absence of the regular distribution of the amorphous domains. A new concept to prepare cellulose nanomaterials was reported, whereby enzymatic hydrolysis was used in combination with mechanical shearing and high-pressure homogenization, leading to a controlled fibrillation down to the nanoscale, to produce cellulose nanomaterials with a diameter of $\sim 5-6 \mathrm{~nm} .{ }^{33}$ Bacterial CNCs were also reportedly isolated using a commercially available cellulase enzyme in combination with mechanical shearing, which is depicted in Figure $2 .{ }^{34}$ The nanocrystals prepared by this route exhibited better mechanical and thermal properties as compared to the nanocrystals obtained from sulfuric acid hydrolysis.

Prolonged hydrolysis can lead to further reduction in the molecular weight, and hence, to obtain CNCs, acid hydrolysis has to be stopped after attaining LODP. ${ }^{35}$ Highly crystalline
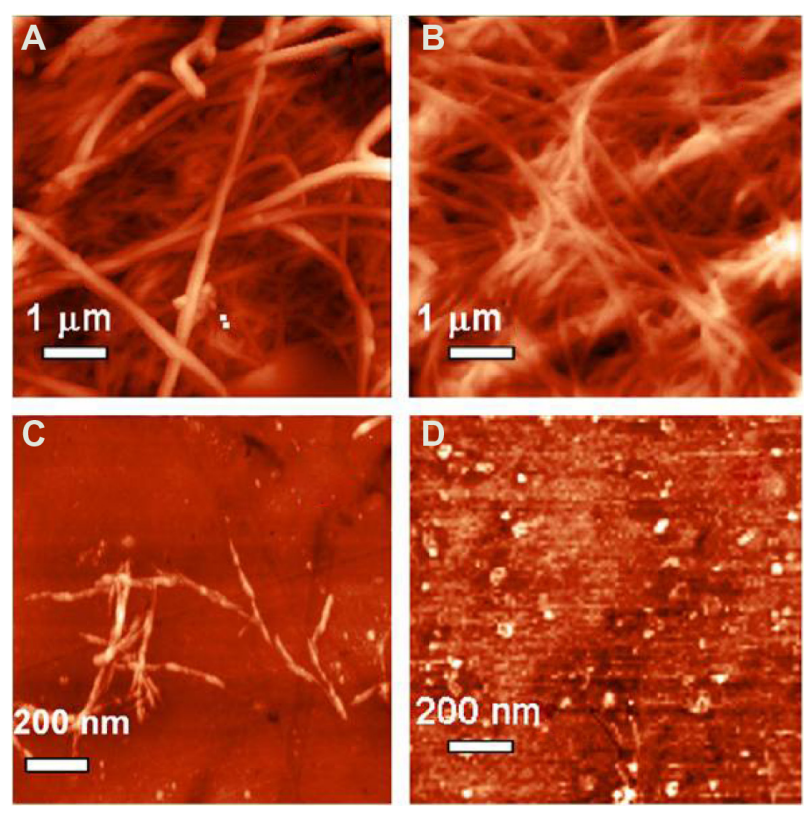

Figure 2 Bacterial cellulose nanocrystals isolated using a commercially available cellulase enzyme in combination with mechanical shearing.

Notes: AFM images of bacterial cellulose fibers (A), bacterial cellulose fibers after mechanical disintegration (B), bacterial cellulose nanocrystals obtained by enzyme treatment after 12 hours (C) and debris obtained after complete hydrolysis (D). Reprinted from George J, Ramana KV, Bawa AS, Siddaramaiah. Bacterial cellulose nanocrystals exhibiting high thermal stability and their polymer nanocomposites. Inter J Biol Macromol, 201 1;48:50-57.34 Copyright (C) 201I, with permission from Elsevier Limited.

Abbreviation: AFM, atomic force microscopy. cellulose domains are resistant to hydrolysis for a longer time compared to disordered or amorphous regions and hence, they can be easily separated from the acid medium. The processing conditions used during the hydrolysis process, such as reaction time, the temperature used, etc, are very critical in controlling the yield and quality of CNCs. If the hydrolysis time is inadequate, then amorphous fractions remain, which may result in the reduction of crystallinity and change in particle morphology. Similarly, allowing the reaction to continue for a long time can lead to depolymerization of crystalline cellulose, which decreases the aspect ratio of the nanocrystals. Temperature is also a critical factor as higher reaction temperatures prove to be effective in obtaining shorter $\mathrm{CNCs}^{36}$

\section{Dimensions of CNCs}

The geometric dimensions of CNCs, such as length and width, may vary depending on the origin of cellulose microfibrils and the acid hydrolysis conditions such as time, temperature, purity, etc. $\mathrm{CNC}$ exhibits a relatively broad distribution in length and width because of the diffusion-controlled nature of the hydrolysis process. The dimensions of CNCs depending on the source and preparation method are summarized in Table 1.

The average length of the rod-shaped particle can vary from tens of nanometers to several micrometers, while width ranges from $3 \mathrm{~nm}$ to $50 \mathrm{~nm}$. CNCs obtained from wood were reported to have diameter and length in the range of 3-5 $\mathrm{nm}$ and 100-300 nm, respectively. ${ }^{37} \mathrm{CNCs}$ obtained from cotton were found to have diameter of 5-10 nm and length of 100-150 nm, while that of Ramie is $70-200 \mathrm{~nm}$ and 5-15 nm, respectively. ${ }^{38,39}$ Similarly CNC from sisal exhibited length in the range of $100-300 \mathrm{~nm}$ and diameter in the range of $3-5 \mathrm{~nm} .{ }^{40}$ Sea algae, such as Valonia ventricosa, produce CNCs having dimensions in the range of $20 \mathrm{~nm}$ diameter and 1,000-2,000 $\mathrm{nm}$ length, while sea animals such as tunicates produce nanocrystals with 10-20 nm diameter and 500-2,000 nm length. ${ }^{41,42} \mathrm{CNCs}$ produced from bacterial cellulose by $\mathrm{HCl}$ hydrolysis were found to have their diameter and length in the range of 10-20 nm and 100-300 nm, respectively, while $\mathrm{H}_{2} \mathrm{SO}_{4}$ hydrolysis, produced bacterial $\mathrm{CNC}$ with a higher aspect ratio. ${ }^{43,44}$ The geometrical aspect ratio of CNCs, which is the ratio of length to diameter (L/D), is very important in defining the reinforcing capability of CNCs. CNCs having a high aspect ratio generally show better reinforcing ability. The aspect ratio also plays an important role in the formation of percolated networks that improve the mechanical performances of polymer nanocomposites. ${ }^{45}$

\section{Properties of CNCs}

The important properties of CNCs can be described under three main categories, which are briefly discussed as follows. 
Table I Overview of the dimensions of cellulose nanocrystals depending on the source and preparation method

\begin{tabular}{|c|c|c|c|c|c|}
\hline Source & Preparation method & Length (nm) & Width (nm) & $\begin{array}{l}\text { Aspect } \\
\text { ratio (L/D) }\end{array}$ & Reference \\
\hline Wood & $\mathrm{H}_{2} \mathrm{SO}_{4}$ hydrolysis & $100-300$ & $3-5$ & $20-100$ & 37,45 \\
\hline Cotton & $\mathrm{HCl}$ hydrolysis & $100-150$ & $5-10$ & $10-30$ & 38 \\
\hline Ramie & $\mathrm{H}_{2} \mathrm{SO}_{4}$ hydrolysis & $70-200$ & $5-15$ & $\sim 12$ & 39 \\
\hline Sisal & $\mathrm{H}_{2} \mathrm{SO}_{4}$ hydrolysis & $100-300$ & $3-5$ & $\sim 60$ & 40 \\
\hline Valonia & $\mathrm{H}_{2} \mathrm{SO}_{4}$ hydrolysis & $\mathrm{I}, 000-2,000$ & $10-20$ & $50-200$ & 41 \\
\hline Tunicates & $\mathrm{H}_{2} \mathrm{SO}_{4}$ hydrolysis & $>1,000$ & $10-20$ & $\sim 100$ & 42 \\
\hline Bacteria & $\mathrm{H}_{2} \mathrm{SO}_{4}$ hydrolysis & $100-1,000$ & $10-50$ & $2-100$ & 43 \\
\hline Bacteria & $\mathrm{HCl}$ hydrolysis & $160-420$ & $15-25$ & $7-23$ & 44 \\
\hline
\end{tabular}

Abbreviation: L/D, length:diameter.

\section{Mechanical properties}

The limitations in measuring the mechanical properties of nanomaterials along multiple axes have made the quantitative evaluation of the tensile modulus and strength of CNC extremely challenging. In addition to this, different factors such as anisotropy, defects in the nanocrystals, percentage crystallinity, dimensions of the samples, and so on can also affect the results. Theoretical calculations and indirect experimental measurements using atomic force microscopy (AFM), X-ray diffraction analysis, inelastic X-ray scattering, Raman scattering, etc were used to calculate the elastic properties of CNC. ${ }^{46}$ The theoretical tensile strength of CNCs was found to be in the range of 7.5-7.7 GPa, which is much more than that of steel wire and Kevlar ${ }^{\circledR}-49 .{ }^{46}$ In another study, the elastic modulus of the $\mathrm{CNC}$ obtained from tunicates was determined using AFM, whereby the AFM tip was used to perform a three-point bending test. The elastic moduli of $\mathrm{CNCs}$ were found to be $\sim 150 \mathrm{GPa} .{ }^{47}$ Using AFM, the transverse elastic modulus of CNCs was also determined by comparing the experimental force-distance curves with three-dimensional finite elemental calculations. ${ }^{48}$ This measurement proved that the transverse modulus of an individual $\mathrm{CNC}$ lies in the range of 18-50 GPa. The deformation micromechanics analysis of tunicate cellulose whiskers using Raman spectroscopy proved that the calculated modulus of tunicate $\mathrm{CNC}$ is $\sim 143 \mathrm{GPa}^{49}$

\section{Liquid crystalline nature of CNCs}

Under suitable conditions and at critical concentrations, all asymmetric rod-like or plate-like particles spontaneously form ordered structures, leading to the formation of a nematic phase. Rod-like CNCs, when dispersed in water, self-align to form chiral nematic phases with liquid crystalline properties. Their stiffness, aspect ratios, and the ability to align under certain conditions make them ideal for exhibiting liquid crystalline behavior. However, cellulose crystallites are known to have a helical twist down the long axis, similar to a screw, which can either lead to a chiral nematic or a cholesteric phase of stacked planes aligned along a perpendicular axis depending on the concentration. ${ }^{46}$ Various factors such as size, charge, shape, dispersity, electrolyte, and external stimuli can also affect the liquid crystallinity of CNC. The liquid crystallinity of nanocrystals coupled with the birefringent nature leads to interesting optical phenomena. The type of acid used for hydrolysis can also affect the liquid crystalline nature. $\mathrm{CNC}$ obtained by sulfuric acid hydrolysis often possesses a negatively charged surface, which promotes uniform dispersion in water due to electrostatic repulsions. ${ }^{50}$ Even though the interactions between nanocrystals are strong, highly sulfonated $\mathrm{CNC}$ is readily dispersible and this leads to the development of lyotropic behavior. ${ }^{51}$ Sulfuric acid- and phosphoric acid-derived CNCs normally give chiral nematic structure, whereas hydrochloric acid-derived CNCs with postreaction sulfonation give rise to a birefringent glassy phase.

\section{Rheological properties}

Rheological parameters of CNC are influenced by properties such as liquid crystallinity, ordering, and gelation properties. Dilute CNC suspensions show shear thinning behavior, which shows concentration dependence at low rates. At higher concentrations, in which the suspensions are lyotropic, they exhibit anomalous behavior. The main reason for such behavior is that the rod-shaped nanocrystals tend to align at a critical shear rate. As the shear rate reaches a critical point, the chirality of the $\mathrm{CNC}$ suspension breaks down in favor of a simple nematic structure. ${ }^{52} \mathrm{In}$ addition, the relaxation time constant depends on the aspect ratio, and $\mathrm{CNCs}$ with higher aspect ratios stay aligned for longer times even after shear. The type of acid used for hydrolysis can also influence the rheological properties of CNC suspensions. Sulfuric acid-treated crystals show some shear thinning that is independent of time, while $\mathrm{HCl}$ derived crystals show much higher shear thinning behavior, 
anti-thixotropy at lower concentrations and thixotropy at higher concentrations. ${ }^{53}$

\section{Surface modification of CNCs}

CNCs have very high surface-to-volume ratios, as well as plenty of hydroxyl groups, which make it suitable for many types of surface functionalizations. By introducing any chemical functionality on their surface, the type of interactions that the material exhibits with its surroundings can be modified. Commonly used surface functionalizations for CNCs are esterification, etherification, oxidation, amidation, carbamation, nucleophilic substitution, silylation, polymer grafting, etc. ${ }^{54}$ The main advantage of chemical functionalization is that it can introduce either negative or positive electrostatic charges on the CNC surface, which ultimately provides better dispersion in any solvent/polymer. It also helps to tune the surface energy characteristics to improve compatibility, especially when used along with nonpolar or hydrophobic polymer matrices. ${ }^{2}$ Esterification involves the conversion of the surface hydroxyls of cellulose to esters. Sulfation and phosphorylation are some commonly used esterification reactions for cellulose. Etherification is another important chemical modification, and the most common practice is to use glycidyltrimethylammonium chloride or its derivatives to cationize the surface of the cellulose. ${ }^{55}$ Mild alkaline cationization conditions preserve the crystalline morphology and dimensions of CNCs. ${ }^{56}$ Surface-carboxylated CNCs with different sizes and degrees of oxidation were synthesized using TEMPO (2,2,6,6-Tetramethylpiperidin-1-yl)oxyl)-mediated oxidation of cotton. ${ }^{57}$ In the amidation technique, oxidized CNCs were used as the starting material, whereby carboxylic acid moieties were converted into amide products by reacting them with a primary amine. ${ }^{58}$ Araki et al applied this technique to bind poly(ethylene glycol) covalently with the cellulose surface and stabilized suspensions of CNCs in various solvents were synthesized..$^{38}$ In the carbamation reaction, isocyanates were used to modify CNCs. The surface modification of CNCs using isocyanates was reported by Siqueira et al, who modified sisal-based CNCs with $n$-octadecyl isocyanate without any catalyst. ${ }^{59}$ Silanes can also be grafted onto CNCs, which is one technique used to enhance the interactions with polymer matrices. Perhaps, chemical modification of CNCs is most useful in the area of fabricating polymer nanocomposite materials. However, the main challenge in this process lies in preserving the original morphology and maintaining the integrity of the CNCs.

\section{Applications of CNCs}

$\mathrm{CNC}$ is a suitable nanomaterial for a wide range of applications, such as enzyme immobilization, synthesis of antimicrobial and medical materials, green catalysis, biosensing, synthesis of drug carrier in therapeutic and diagnostic medicine, etc. ${ }^{60,61}$ These nanomaterials offer several potential advantages as drug delivery excipients due to their properties such as smaller size, hydrophilicity, biocompatibility, etc. ${ }^{62}$ Due to their very large surface area and possibility of acquiring negative charge during hydrolysis, large quantities of drugs can be bound to the surface of these materials with the potential for optimal control of dosing. ${ }^{62}$ In one such report, CNCs prepared from softwood were used to bind ionizable drugs such as tetracycline and doxorubicin, which could be released rapidly over a 1 -day period. ${ }^{63}$ The abundant surface hydroxyl groups present in nanocrystals provide sites for surface modification with a range of chemical groups. Surface modification can be used to modulate the loading and release of drugs that do not normally bind to cellulose, such as nonionized or hydrophobic drugs. ${ }^{64} \mathrm{CNC}$-based aerogels are also receiving growing interest in biomedical and pharmaceutical applications due to their open pore structure and high surface area, which can provide enhanced drug bioavailability and better drug-loading capacity. ${ }^{65}$ Highly porous nanocellulose aerogel scaffolds were reported to attain sustained drug release, which also revealed new possibilities as carriers for controlled drug delivery. ${ }^{66}$

The utilization of CNCs for various applications can be of two broad types: one type involves the use of functionalized or nonfunctionalized as-synthesized $\mathrm{CNC}$, and the other one involves the use of polymer nanocomposites wherein $\mathrm{CNC}$ acts as a reinforcing agent. As a result of their distinctive properties, as-synthesized $\mathrm{CNCs}$ have the potential for being used in various and diverse applications ranging from products such as nanopaper, barrier films, and $\mathrm{pH}$ sensors, to stabilization of oil/water interfaces, to production of Pickering emulsions with outstanding stability, etc, but CNC-containing polymer nanocomposites has many more applications. ${ }^{67-70}$

A polymer nanocomposite is a multiphase material wherein the polymer phase is reinforced with a nanomaterial. These polymer nanocomposites exhibit unique properties because of their nanometric size and the increased surface area of the reinforcing material. CNC is used as the loadbearing constituent in many polymer nanocomposite systems as it can produce significant improvements in mechanical properties even at very low volume fractions. Furthermore, its high aspect ratio, good dispersion in hydrophilic systems, 
and the capability to form percolated network-type architecture within the polymer matrix make it a widely preferred reinforcing component. In the area of polymer nanocomposites, CNCs are also used as model nanofillers with a defined morphology to impart sufficient strength and modulus. Both natural and synthetic polymers are used for the fabrication of nanocomposites. Several natural polymers, such as starch, chitosan, natural rubber, cellulose acetate butyrate, carboxymethyl cellulose, hydroxypropyl methylcellulose, gelatin, and soy protein, are used in the preparation of nanocomposites. ${ }^{71-77}$ Similarly, several synthetic polymers such as polyvinyl alcohol (PVA), polyvinyl chloride, polyethylene, polycaprolactone, polypropylene, and polyurethane are also used. $^{78-82}$

The main challenge in achieving excellent performance lies in attaining homogeneous dispersion of nanocrystals within the polymer matrix and a good matrix-filler interaction. Good dispersibility of the CNCs in the polymer matrix is a prerequisite to make polymer nanocomposites with better properties, as a nonhomogeneous dispersion of the filler in the polymer matrix decreases the final mechanical properties of the nanocomposite material. ${ }^{83} \mathrm{CNCs}$ can form stable colloidal dispersions in water and hence they are best suited for water-soluble or water-dispersible polymers such as latexes. However, stable cellulose nanoparticle dispersions in nonpolar solvents can also be obtained by using either surfactants or surface chemical grafting. Among these, the use of the polymer grafting method is better in some cases due to the presence of the covalent linkage between the compatibilizer and the nanocrystal. ${ }^{84}$ In addition, if the grafted chains and the matrix are the same, better compatibilization can be obtained due to the formation of a co-continuous phase.

With the help of the chemical grafting method, various functional molecules such as fluorescent molecules, DNA, etc can also be attached on the surface of $\mathrm{CNCs}$, which can be used for anchoring in a biological environment. It is also possible to disperse cellulose whiskers in an organic solvent without either addition of a surfactant or any chemical modification. ${ }^{85}$ Moreover, in some cases, better dispersion of CNCs leads to the formation of a percolated network of nanocrystals within the polymer matrix, which also contributes to enhancement in the properties of polymer nanocomposites.

These types of nanocomposites are used for making biomimetic foams, toughened paper, flexible panels for flat panel displays, water repellents, and high-security papers. ${ }^{86-89}$ They are also useful for various biomedical applications such as wound healing patches, tissue engineering scaffolds, and hydrogels for clinical and pharmacological applications, etc.
Considering the biocompatibility of $\mathrm{CNC}$ and the possibility of chemical modifications such as fluorescent labeling, CNCs are potentially useful in the field of biomedical applications such as biosensors, bioprobes, fluorescence bioassays, bioimaging applications, and so on. ${ }^{90}$ Fluorescently labeled $\mathrm{CNCs}$ enable the use of fluorescence techniques to study the interaction between CNCs and living cells in vivo. ${ }^{91} \mathrm{CNCs}$ are also capable of forming highly functional nanocomposites for applications such as ultrathin film-coating materials. ${ }^{92}$ $\mathrm{CNC}$ can also be used for stabilizing nanoparticles of specific functionality for specific applications. CNC-containing polymer nanocomposites is also used for developing membranes, fibers, textiles, batteries, supercapacitors, electroactive polymers, and sensors and actuators that utilize electromechanical responses. ${ }^{93,94}$ One future area of application wherein CNC-containing polymer nanocomposites can make an impact is in the field of biodegradable packaging materials. The incorporation of CNC can significantly improve the mechanical performance, thermal stability, and barrier and optical properties due to its improved crystallinity and better interfacial interaction. Biodegradable nanocomposite films with superior properties can also find their applications in food and biomedical packaging areas, in which lower permeability to moisture, gases, aroma, and oil are very much needed. ${ }^{95}$ In one research investigation, PVA-based barrier membranes containing different amounts of CNCs have been reported. ${ }^{96}$ These membranes containing up to 10 weight percentage of $\mathrm{CNCs}$ have been found to reduce the water vapor transmission rate. The presence of highly crystalline nanocrystals can increase the tortuosity of water vapor within the polymer, leading to a slower diffusion process and, hence, lower permeability. The barrier properties are enhanced if the filler is less permeable and has good dispersion in the matrix along with a high aspect ratio. However, many scientific and technological challenges have to be addressed in several areas, such as optimizing suitable processing technologies for reducing the production cost, establishing the compatibility between products and packaging materials, meeting several packaging legislations, etc, before achieving a truly biodegradable packaging material that satisfies both industry requirements and consumer expectations.

\section{Conclusion}

$\mathrm{CNC}$ is unique among a range of other nanostructured materials due to its benefits such as being a renewable, sustainable, nontoxic, and biocompatible nanomaterial. Due to its nanometric dimensions, large aspect ratio, and excellent mechanical and chemical properties, $\mathrm{CNC}$ has many potential 
applications in many areas, including materials science, electronics, and medicine. The emerging industrial extraction processes to obtain $\mathrm{CNC}$ in large quantities need to be optimized to achieve greater yield and quality. So far, most of the research has focused on characterizing the morphological, mechanical, optical, and liquid crystalline properties of $\mathrm{CNC}$, but exploring various surface modification processes to manipulate the functionality of $\mathrm{CNC}$ without affecting its inherent properties will be the main focus of future research. This approach will make CNC attractive for use in a wide range of industrial applications, such as high-performance biodegradable material science, electronics, biomedical engineering, drug delivery, catalysis, etc. Innovations in this area may lead to versatile nanomaterials with improved properties. In polymer nanocomposite systems, attaining uniform dispersion and distribution of $\mathrm{CNC}$ in a polymer matrix is still a challenging issue, as aggregation or agglomeration is commonly encountered. A tailor-made chemical modification process is necessary to incorporate $\mathrm{CNC}$ into different polymer matrix systems effectively. Innovations in nanotechnology related to renewable nanomaterials such as CNC are anticipated to provide technologically advanced products that are not harmful to the environment.

\section{Disclosure}

The authors report no conflicts of interest in this work.

\section{References}

1. Klemm D, Heublein B, Fink HP, Bohn A. Cellulose: fascinating biopolymer and sustainable raw material. Angew Chem Int Ed. 2005;44:3358-3393.

2. Habibi Y, Lucia LA, Rojas OJ. Cellulose nanocrystals: chemistry, selfassembly, and applications. Chem Rev. 2010;110:3479-3500.

3. Sjostrom E. Wood Chemistry: Fundamentals and Applications. 2nd ed. California: Academic Press Inc; 1993.

4. Lavoine N, Desloges I, Dufresne A, Bras J. Microfibrillated celluloseIts barrier properties and applications in cellulosic materials: A review. Carbohydr Polym. 2012;90:735-764.

5. George J, Sabapathi SN, Siddaramiah. Water Soluble Polymer-Based Nanocomposites Containing Cellulose Nanocrystals. In Thakur VK, Thakur MK (eds) Eco-friendly Polymer Nanocomposites, Springer India, New Delhi 2015;75:259-293.

6. Eichhorn SJ, Baillie CA, Zafeiropoulos N, Mwaikambo LY, Ansell MP, et al. Review: current international research into cellulosic fibres and composites. J Mater Sci. 2001;36:2107-2131.

7. Mihranyan A. Cellulose from cladophorales green algae: from environmental problem to high-tech composite materials. J Appl Polym Sci. 2011;119:2449-2460.

8. Sugiyama J, Vuong R, Chanzy H. Electron diffraction study of the two crystalline phases occurring in native cellulose from an algal cell wall. Macromol. 1991;24:4168-4175.

9. Masaoka S, Ohe T, Sakota N. Production of cellulose from glucose by Acetobacterxylinum. J. Ferment Bioeng. 1993;75:18-22.

10. George J, Ramana KV, Sabapathy SN, Bawa AS. Physicomechanical properties of chemically treated bacterial (Acetobacterxylinum) cellulose membrane. World J Microbiol Biotechnol. 2005;21:1323-1327.
11. George J, Ramana KV, Sabapathy SN, Jagannath JH, Bawa AS. Characterization of chemically treated bacterial (Acetobacterxylinum) biopolymer: Some thermo-mechanical properties. Int J Biol Macromol. 2005;37:189-194.

12. Brown Jr, RM. Bacterial cellulose. In Kennedy, Philips, Williams (eds) Cellulose: structural and functional aspects. Ellis Horwood, Chichester, 1989;145-151.

13. Zhao Y, Li J. Excellent chemical and material cellulose from tunicates: diversity in cellulose production yield and chemical and morphological structures from different tunicate species. Cellulose. 2014;21: 3427-3441.

14. Frey-Wyssling A. The fine structure of cellulose microfibrils. Science. 1954;119:80-82.

15. Peterlin A. Ingram P. Morphology of secondary wall fibrils in cotton. Textile Res J. 1970;40:345-354.

16. Mazeau K, Heux L. Molecular dynamics simulations of bulk native crystalline and amorphous structures cellulose. J Phys Chem B. 2003;107:2394-2404.

17. Brinchi L, Cotana F, Fortunati E, Kenny JM. Production of nanocrystalline cellulose from lignocellulosic biomass: technology and applications. Carbohydr Polym. 2013;94:154-169.

18. Atalla RH, Vanderhart DL. Native cellulose: a composite of two distinct crystalline forms. Science. 1984;223:283-285.

19. Debzi EM, Chanzy H, Sugiyama J, Tekely P, Excoffier G. The I $\alpha \rightarrow I \beta$ transformation of highly crystalline cellulose by annealing in various mediums. Macromol. 1991;24:6816-6822.

20. Newman RH, Hemmingson JA. Carbon-13 NMR distinction between categories of molecular order and disorder in cellulose. Cellulose. 1995;2:95-110.

21. Domingues RM, Gomes ME, Reis RL. The potential of cellulose nanocrystals in tissue engineering strategies. Biomacromolecules. 2014; 15:2327-2346.

22. de Souza Lima MM, Borsali R. Rod like cellulose microcrystals: Structure, properties and applications. Macromol Rapid Comm. 2004;25:771-787.

23. Sacui IA, Nieuwendaal RC, Burnett DJ, Stranick SJ, Jorfi M. et al. Comparison of the properties of cellulose nanocrystals and cellulose nanofibrils isolated from bacteria, tunicate, and wood processed using acid, enzymatic, mechanical, and oxidative methods. ACS Appl Mater Interfaces. 2014;6:6127-6138

24. Ranby BG. The colloidal properties of cellulose micelles. Discuss Faraday Soc. 1951;11:158-164.

25. Mukherjee SM, Sikorski J, Woods HJ. Electron microscopy of degraded cellulose fibers. J Text Inst. 1952;43:T196-T201.

26. Mukherjee SM, Woods HJ. X-ray and electron microscope studies of the degradation of cellulose by sulphuric acid. Bio chim Bio phys Acta. 1953;10:499-511.

27. Battista OA, Smith PA. Microcrystalline cellulose. J Ind Eng Chem. 1962;54:20-29.

28. Marchessault RH, Morehead FF Koch JM. Hydrodynamics properties of neutral suspensions of cellulose crystallites as related to size and shape. J Colloid Sci. 1961;16:327-344.

29. Battista OA. Hydrolysis and crystallization of cellulose. Ind Eng Chem. 1950;42:502-507.

30. Nishiyama Y, Kim UJ, Kim DY, Katsumata KS, May RP, Langan P. Periodic disorder along ramie cellulose microfibrils. Biomacromolecules. 2003;4:1013-1017.

31. Battista OA, Coppick S, Howsmon JA, Morehead FF, Sisson WA. Level off degree of polymerization. Ind Eng Chem. 1956;48:333-335.

32. Kai A. The fine structure of valoniamicrofibril gel permeation chromatographic studies of valonia cellulose. Sen-i Gakkaishi. 1976;32:T326-T334.

33. Paakko M, Ankerfors M, Kosonen H, Nykanen A, Ahola S. et al. Enzymatic hydrolysis combined with mechanical shearing and highpressure homogenization for nanoscale cellulose fibrils and strong gels. Biomacromolecules. 2007;8:1934-1941.

34. George J, Ramana KV, Bawa AS, Siddaramaiah. Bacterial cellulose nanocrystals exhibiting high thermal stability and their polymer nanocomposites. Inter J Biol Macromol, 2011;48:50-57. 
35. Hakansson H, Ahlgren P. Acid hydrolysis of some industrial pulps: effect of hydrolysis conditions and raw material. Cellulose. 2005; 12:177-183.

36. Elazzouzi-Hafraoui S, Nishiyama Y, Putaux JL, Heux L, Dubreuil F, Rochas C. The shape and size distribution of crystalline nanoparticles prepared by acid hydrolysis of native cellulose. Biomacromol. 2008;9:57-65.

37. Beck-Candanedo S, Roman M, Gray DG. Effect of reaction conditions on the properties and behavior of wood cellulose nanocrystal suspensions.Biomacromolecules. 2005;6:1048-1054.

38. Araki J, Wada M, Kuga S. Steric stabilization of a cellulose microcrystal suspension by poly (ethylene glycol) grafting.Langmuir. 2001;17:21-27.

39. de Menezes AJ, Siqueira G, Curvelo AA, Dufresne A. Extrusion and characterization of functionalized cellulose whiskers reinforced polyethylene nanocomposites. Polymer. 2009;50:4552-4563.

40. De Rodriguez NLG, Thielemans W, Dufresne A. Sisal cellulose whiskers reinforced polyvinyl acetate nanocomposites. Cellulose. 2006;13:261-270

41. Revol J.-F, On the cross-sectional shape of cellulose crystallites in Valoniaventricosa.Carbohydr Polym. 1982;2:123-134.

42. Kimura F,Kimura T,Tamura M,Hirai A,IkunoM, Horii F, Magnetic alignment of the chiral nematic phase of a cellulose microfibril suspension. Langmuir. 2005;21:2034-2037.

43. George J, Bawa AS, Siddaramiah. Synthesis and characterization of bacterial cellulose nanocrystals and their PVA nanocomposites. Adv Mater Res. 2010;123:383-386.

44. George J, Siddaramaiah. High performance edible nanocomposite films containing bacterial cellulose nanocrystals. Carbohydr Polym. 2012;87:2031-2037.

45. Peng BL, Dhar N, Liu HL, Tam KC. Chemistry and applications of nanocrystalline cellulose and its derivatives: a nanotechnology perspective. Can J Chem Eng. 2011;9999:1-16.

46. Moon RJ, Martini A, Nairn J, Simonsen J, Youngblood J. Cellulose nanomaterials review: structure, properties and nanocomposites. Chem Soc Rev. 2011;40:3941-3994.

47. Iwamoto S, Kai W, Isogai A, Iwata T. Elastic modulus of single cellulose microfibrils from tunicate measured by atomic force microscopy. Biomacromol. 2009;10:2571-2576.

48. Lahiji RR, Xu X, Reifenberger R, Raman A, Rudie A, Moon RJ. Atomic force microscopy characterization of cellulose nanocrystals. Langmuir. 2010;26:4480-4488.

49. Sturcova A, Davies GR, Eichhorn SJ. Elastic modulus and stresstransfer properties of tunicate cellulose whiskers. Biomacromol. 2005;6:1055-1061.

50. Revol JF, Bradford H, Giasson J, Marchessault RH, Gray DG. Helicoidal self-ordering of cellulose microfibrils in aqueous suspension. Int J Biol Macromol. 1992;14:170-172.

51. Orts WJ, Godbout L, Marchessault RH, Revol JF. Enhanced ordering of liquid crystalline suspensions of cellulose microfibrils: A small angle neutron scattering study. Macromol. 1998;31:5717-5725.

52. Azizi Samir MAS, Alloin F, Sanchez JY, El Kissi N, Dufresne A. Preparation of cellulose whiskers reinforced nanocomposites from an organic medium suspension. Macromol. 2004;37:1386-1393.

53. Araki J, Wada M, Kuga S, Okano T. Influence of surface charge on viscosity behavior of cellulose microcrystal suspension. J Wood Sci. 1999;45:258-261.

54. Eyley S, Thielemans W. Surface modification of cellulose nanocrystals. Nanoscale, 2014;6:7764-7779.

55. Zaman M. Xiao H. Chibante F, Ni Y. Synthesis and characterization of cationically modified nanocrystalline cellulose. Carbohydr Polym. 2012;89:163-170.

56. Hasani M. Cranston ED, Westman G, Gray DG. Cationic surface functionalization of cellulose nanocrystals. Soft Matter, 2008;4:2238-2244.

57. Montanari S, Roumani M, Heux L, Vignon MR. Topochemistry of carboxylated cellulose nanocrystals resulting from TEMPO-mediated oxidation. Macromol. 2005;38:1665-1671.
58. Azzam F, Heux L, Putaux JL, Jean B. Preparation by grafting onto, characterization, and properties of thermally responsive polymer-decorated cellulose nanocrystals. Biomacromol. 2010;11:3652-3659.

59. Siqueira G, Bras J, Dufresne A. Cellulose whiskers versus microfibrils: influence of the nature of the nanoparticle and its surface functionalization on the thermal and mechanical properties of nanocomposites. Biomacromol. 2008;10:425-432.

60. Romany M, Shuping D, Hirani A, Yong WL. Cellulose nanocrystals for drug delivery. In ACS symposium series. Oxford University Press. 2009; 1017:81-91.

61. Lam E, Male KB, Chong JH, Leung AC, Luong JH. Applications of functionalized and nanoparticle-modified nanocrystalline cellulose. Trends Biotechnol. 2012;30:283-290.

62. Taheri A. Mohammadi M. The Use of Cellulose Nanocrystals for Potential Application in Topical Delivery of Hydroquinone. Chem Biol Drug Des. 2015;86:102-106.

63. Jackson JK, Letchford K, Wasserman BZ, Ye L, Hamad WY, Burt HM. The use of nanocrystalline cellulose for the binding and controlled release of drugs. Int J Nanomedicine. 2011;6:321

64. Akhlaghi SP, Berry RC, Tam KC. Surface modification of cellulose nanocrystal with chitosan oligosaccharide for drug delivery applications. Cellulose. 2013;20:1747-1764.

65. Garcia-Gonzalez CA, Alnaief M, Smirnova I. Polysaccharide-based aerogels_-Promising biodegradable carriers for drug delivery systems. Carbohydr Polym. 2011;86:1425-1438.

66. Valo H, Arola S, Laaksonen P, Torkkeli M, Peltonen L, et al. Drug release from nanoparticles embedded in four different nanofibrillar cellulose aerogels. Eur J Pharm Sci. 2013;50:69-77.

67. Nogi M, Iwamoto S, Nakagaito AN, Yano H. Optically transparent nanofiber paper. Adv Mater. 2009;21:1595-1598.

68. Belbekhouche S, Bras J, Siqueira G, Chappey C, Lebrun L, et al. Water sorption behavior and gas barrier properties of cellulose whiskers and microfibrils films. Carbohydr Polym. 2011;83:1740-1748.

69. Nielsen LJ, Eyley S, Thielemans W, Aylott JW. Dual fluorescent labelling of cellulose nanocrystals for $\mathrm{pH}$ sensing. Chem Comm. 2010;46:8929-8931.

70. Kalashnikova I, Bizot H, Cathala B, Capron I. Modulation of cellulose nanocrystals amphiphilic properties to stabilize oil/water interface. Biomacromol. 2011;13:267-275.

71. Mathew AP, Dufresne A. Morphological investigation of nanocomposites from sorbitol plasticized starch and tunicin whiskers. Biomacromol. 2002;3:609-617.

72. deMesquita JP, Donnici CL, Pereira FV. Biobased nanocomposites from layer-by-layer assembly of cellulose nanowhiskers with chitosan. Biomacromol. 2010;11:473-480.

73. Bendahou A, Habibi Y, Kaddami H, Dufresne A. Physico-chemical characterization of palm from phoenix dactylifera-L, preparation of cellulose whiskers and natural rubber-based nanocomposites. J Biobased Mater Bio. 2009;3:81-90.

74. Grunert M, Winter WT. Nanocomposites of cellulose acetate butyrate reinforced with cellulose nanocrystals. J Polym Environ. 2002;10:27-30.

75. Choi Y, Simonsen J. Cellulose nanocrystal-filled carboxymethyl cellulose nanocomposites. J Nanosci Nanotechnol. 2006;6: 633-639.

76. George J, Kumar R, Sajeevkumar VA, Ramana KV, Rajamanickam R, et al. Hybrid HPMC nanocomposites containing bacterial cellulose nanocrystals and silver nanoparticles. Carbohydrpolym. 2014;105: 285-292.

77. Wang Y, Cao X, Zhang L. Effects of cellulose whiskers on properties of soy protein thermoplastics. Macromol Biosci. 2006;6:524-531.

78. George J, Sajeevkumar VA, Ramana KV, Sabapathy SN, Siddaramaiah. Augmented properties of PVA hybrid nanocomposites containing cellulose nanocrystals and silver nanoparticles. J Mater Chem. 2012;22:22433-22439.

79. Chazeau L, Cavaille JY, Canova G, Dendievel R, Boutherin B. Viscoelastic properties of plasticized PVC reinforced with cellulose whiskers. J Appl Polym Sci. 1999;71:1797-1808. 
80. Goffin AL, Raquez JM, Duquesne E, Siqueira G, Habibi Y, et al. Poly ( $\varepsilon$-caprolactone) based nanocomposites reinforced by surface-grafted cellulose nanowhiskers via extrusion processing: Morphology, rheology, and thermo-mechanical properties. Polymer. 2011;52:1532-1538.

81. Ljungberg N, Bonini C, Bortolussi F, Boisson C, Heux L, Cavaille JY. New nanocomposite materials reinforced with cellulose whiskers in atactic polypropylene: effect of surface and dispersion characteristics. Biomacromol. 2005;6:2732-2739.

82. Cao X, Dong H, Li CM. New nanocomposite materials reinforced with flax cellulose nanocrystals in waterborne polyurethane. Biomacromol. 2007;8:899-904.

83. Hubbe MA, Rojas OJ, Lucia LA, Sain M. Cellulosic nanocomposites: a review. BioResources. 2008;3:929-980.

84. Habibi Y, Goffin AL, Schiltz N, Duquesne E, Dubois P, Dufresne A. Bionanocomposites based on poly ( $\varepsilon$-caprolactone)-grafted cellulose nanocrystals by ring-opening polymerization. J Mater Chem. 2008;18:5002-5010.

85. Azizi Samir MAS, Alloin F, Dufresne A. Review of recent research into cellulosic whiskers, their properties and their application in nanocomposite field. Biomacromol. 2005;6:612-626.

86. Svagan AJ, Samir MASA, Berglund LA. Biomimetic foams of high mechanical performance based on nanostructured cell walls reinforced by native cellulose nanofibrils. Adv Mater. 2008;20:1263-1269.

87. Henriksson M, Berglund LA, Isaksson P, Lindstrom T, Nishino T. Cellulose nanopaper structures of high toughness. Biomacromol. 2008;9:1579-1585.
88. Nogi M, Yano H. Transparent nanocomposites based on cellulose produced by bacteria offer potential innovation in the electronics device industry. Adv Mater. 2008:20:1849-1852.

89. Bayer IS, Fragouli D, Attanasio A, Sorce B, Bertoni G, et al. Waterrepellent cellulose fiber networks with multifunctional properties. $A C S$ Appl Mater Interfaces. 2011;3:4024-4031.

90. Dong S, Roman M. Fluorescentlylabeled cellulose nanocrystals for bioimaging applications. J Am Chem Soc. 2007;129:13810-13811.

91. Mahmoud KA, Mena JA, Male KB, Hrapovic S, Kamen A, Luong JH. Effect of surface charge on the cellular uptake and cytotoxicity of fluorescent labeled cellulose nanocrystals. ACS Appl Mater Interfaces. 2010;2:2924-2932.

92. Hoeger I, Rojas OJ, Efimenko K, Velev OD, Kelley SS. Ultrathin film coatings of aligned cellulose nanocrystals from a convective-shear assembly system and their surface mechanical properties. Soft Matter. 2011;7:1957-1967.

93. Yang H, Tejado A, Alam N, Antal M, van de Ven TG. Films prepared from electrosterically stabilized nanocrystalline cellulose. Langmuir. 2012;28:7834-7842.

94. Wan WK, Hutter JL, Millon L, Guhados G. Bacterial cellulose and its nanocomposites for biomedical applications. In ACS symposium series. Oxford University Press. 2006;938:221-241.

95. Lange J, Wyser Y. Recent innovations in barrier technologies for plastic packaging-a review. PackagTechnol Sci. 2003;16:149-158.

96. Paralikar SA, Simonsen J, Lombardi J. Poly (vinyl alcohol)/cellulose nanocrystal barrier membranes. J Membrane Sci. 2008;320:248-258.
Nanotechnology, Science and Applications

\section{Publish your work in this journal}

Nanotechnology, Science and Applications is an international, peer-reviewed, open access journal that focuses on the science of nanotechnology in a wide range of industrial and academic applications. It is characterized by the rapid reporting across all sectors, including engineering, optics, bio-medicine, cosmetics, textiles, resource sustainability and science. Applied research into nano-materials,

\section{Dovepress}

particles, nano-structures and fabrication, diagnostics and analytics, drug delivery and toxicology constitute the primary direction of the journal. The manuscript management system is completely online and includes a very quick and fair peer-review system, which is all easy to use. Visit http://www.dovepress.com/ testimonials.php to read real quotes from published authors. 